\title{
Hexane Soluble Fraction of Chungpesagan-tang Exhibits Protective Effect against Hypoxia/Reoxygenation-Induced N2a Cell Damage
}

\author{
Kyoung A Kıм ${ }^{1}$, Hwa Jung $\mathrm{CHOI}^{2}$, Bang-Geul Kıм³ ${ }^{3}$, Young-Ran PARK ${ }^{3}$, Ji-Sun Kıм \\ Jae-Ha Rru ${ }^{4}$, and Yunjo SoH ${ }^{2} 3^{*}$ \\ ${ }^{1}$ Department of Oral and MaxilloFacial Radiology, School of Dentistry, Chonbuk National University, Jeon-Ju 561-756, Republic of Korea \\ ${ }^{2}$ Department of Dental Pharmacology, School of Dentistry, Chonbuk National University, Jeon-Ju 561-756, Republic of Korea \\ ${ }^{3}$ Institute of Oral Bioscience, Chonbuk National University, Jeon-Ju 561-756, Republic of Korea \\ ${ }^{4}$ College of Pharmacy, Sookmyung Women's University, Seoul 140-742, Republic of Korea
}

(Received September 3, 2008; Revised October 31, 2008; Accepted November 10, 2008)

\begin{abstract}
Chungpesagan-tang (CST) has been traditionally used in Korea as a therapeutic for cerebral ischemia. To understand the protective mechanism of CST on hypoxia/reoxygenation insults in N2a cells, the cell viability was determined with the treatment of water solution and several solvent fractions of CST. The highest cell viability occurred when the cells were treated with the hexane soluble fraction of CST. Hypoxia/reoxygenation insults were shown to decrease the glutathione peroxidase (GPx) activity and the level of glutathione (GSH) and increase the superoxide dismutase (SOD) activity. However, treatment with hexane soluble fraction of CST ranging from $0.1 \mu \mathrm{g} / \mathrm{ml}$ to $10 \mu \mathrm{g} / \mathrm{ml}$ recovered the activities of GPx and SOD and maintained the levels of MDA and GSH at control levels. While hypoxia/reoxygenation insults induced the activation of ERK in N2a cells, treatment with the hexane soluble fraction of CST inhibited the activation of ERK in a concentration dependent manner. In this study, we were able to demonstrate that the bioactive compounds of CST can be effectively transferred into the hexane soluble fraction, and more importantly that CST exhibits protective effects against hypoxia/reoxygenation insults most likely by recovering redox enzyme activities.
\end{abstract}

Keywords: Chungpesagan-tang, Hypoxia, SOD, GSH, ROS

\section{INTRODUCTION}

Strokes have been ranked as the third most common cause of death worldwide and it has been predicted that cerebrovascular diseases will be the second most frequent cause of death in the future (Huang and McNamara, 2004). The major driving force for the necrotic cell death process appears to the generation of free radicals and peroxynitrite in ischemia/reperfusion tissue ( $\mathrm{Li}$ and Jackson, 2002). The reason for the large number of adverse effects in these diseases can be explained on the basis of the ability of early or late stage damage sites to generate free radicals. Reactive oxygen species (ROS), such as the superoxide ion, hydrogen peroxide and the hydroxyl radical, are thought to play a

${ }^{*}$ Corresponding author

Tel: +82-63-270-4038, Fax: +82-63-270-4037

E-mail: ysoh@chonbuk.ac.kr

The first two authors contributed equally to this work key role in the tissue damage associated with a wide variety of diseases (Floyd, 1999; Lum and Roebuck, 2001; Ushio-Fukai and Alexander, 2004). As a result, ROS have been implicated in neurotoxicity following cerebral ischemia/reperfusion. Accumulation of ROS, particularly superoxide anion $\left(\mathrm{O}_{2}^{-}\right)$and hydrogen peroxide $\left(\mathrm{H}_{2} \mathrm{O}_{2}\right)$, causes damage to membrane phospholipids, proteins and DNA. Under normal circumstances, these oxidant species can be effectively scavenged by antioxidant enzymes, namely superoxide dismutase (SOD) and glutathione peroxidase (GPx) and the resulting $\mathrm{H}_{2} \mathrm{O}_{2}$ product can be subsequently removed by the cytosolic catalase to form water and molecular oxygen (Lee et al., 2004). However, the sudden burst of ROS during cerebral ischemia/reperfusion can overwhelm the antioxidant defense, resulting in lipid peroxidation and hence cerebral infarction (Venardos et al., 2007). Endogenous antioxidant systems are critically important in limiting reoxygenation-induced cellular damage. Therefore, the treatment of ischemic diseases will require maintaining 
the activities of antioxidant enzymes and the levels of related substrates.

Chungpesagan-tang (CST) is one of the most frequently used herbal prescriptions for the treatment of ischemic stroke in oriental medicine (Hong et al., 2000; Hong et al., 1999). but its mode of action is not yet fully understood. In order to investigate the mechanism by which CST exerts its neuroprotective effect, we have used a mouse neuroblastoma (N2a) cell line which has been considered as a useful system to study the neurodegenerative effects of neurotoxic agents (Flaskos et al., 1998).

CST was dispersed in water and fractionated with solvents of different polarity (hexane, chloroform, ethylacetate and butanol) and then redox enzymes activities and the level of glutathione, malondialdehyde were measured in N2a cells treated with CST fractionated in these different solvents. Here, we report that the hexane soluble fraction of CST exhibited the most protective effects against N2a cell damage caused by hypoxia/reoxygenation and our results suggest that this most likely occurred by recovering the redox enzyme activities and maintaining bioactive compounds at control levels.

\section{MATERIALS AND METHODS}

\section{Preparation of Chungpesagan-tang and fraction- ation}

Chungpesagan-tang was composed of a mixture of 8 kinds of crude drugs (Table 1). The mixture was dissolved in water and successively fractionated with hexane, ethylacetate, chloroform and butanol.

\section{Cell culture}

N2a cells were grown on plastic plates or culture

Table I. Composition of Chungpesagan-tang (CST)

\begin{tabular}{cc}
\hline Medicinal Plants & Weight $(\mathrm{g})$ \\
\hline Radix Puerariae & $15.0 \mathrm{~g}$ \\
Radix Scutellariae & $7.5 \mathrm{~g}$ \\
Radix Angelicae Tenuissimae & $7.5 \mathrm{~g}$ \\
Semen Raphani & $3.75 \mathrm{~g}$ \\
Radix Platycodi & $3.75 \mathrm{~g}$ \\
Rhizoma Cimicifugae & $3.75 \mathrm{~g}$ \\
Radix Angelicae & $3.75 \mathrm{~g}$ \\
Rhizoma Rhei & $3.75 \mathrm{~g}$ \\
\hline Total Amount & $48.75 \mathrm{~g}$ \\
\hline
\end{tabular}

dishes in Dulbecco's Modified Eagle's Medium (DMEM) containing $10 \%$ heat-inactivated fetal bovine serum and antibiotics (100 units $/ \mathrm{ml}$ penicillin $\mathrm{G}$ and $100 \mu \mathrm{g} / \mathrm{ml}$ streptomycin) at $37^{\circ} \mathrm{C}$ in $5 \% \mathrm{CO}_{2}$ and $95 \%$ air in a humidified incubator. For hypoxia insults, cells were treated with serum-free, low glucose (1 g/L) DMEM and placed in anaerobic chamber (Thermo Forma, Co. Marietta, $\mathrm{OH}$. USA) for $24 \mathrm{~h}$ containing the following gas mixture: $85 \%$ $\mathrm{N}_{2}, 10 \% \mathrm{H}_{2}$, and $5 \% \mathrm{CO}_{2}$. The cells were then placed in normal incubator containing $5 \% \mathrm{CO}_{2}, 95 \%$ air for $2 \mathrm{~h}$.

\section{Cell viability}

Cell viability was measured using an MTT (3-(4, 5-dimethylthiazolyl-2)-2, 5-diphenyltetrazolium bromide) assay (Huet et al., 1992). Cells $\left(2 \times 10^{4}\right.$ cells/well) were grown in 96-well microtiter plates for $1 \mathrm{~d}$ in regular serum containing media. To determine the protective effects of CST and CST fractions, the cells were treated with various concentrations of CST and CST fractions and subjected to hypoxia/reoxygenation insults as previously described. After incubation of N2a cells for the indicated times, the media was aspirated from the plates and each well was washed with equal volume of phosphate buffered saline. Viability of the remaining N2a cells was determined by the optical density at $540 \mathrm{~nm}$ using a microplate reader (Molecular Devices, Sunnyvale, CA, USA).

\section{Enzyme assays}

Catalase activity was determined by methods described previously (Aebi, 1984). The reaction was performed by adding $150 \mu \mathrm{l}$ of $19 \mathrm{mM}$ hydrogen peroxide to $850 \mu \mathrm{l}$ of $100 \mathrm{mM}$ $\mathrm{KH}_{2} \mathrm{PO}_{4}(\mathrm{pH} 7.0)$ containing $100 \mu \mathrm{g}$ of total cellular protein to achieve a final volume of $1 \mathrm{ml}$. The absorbance at $240 \mathrm{~nm}$ was measured at $25^{\circ} \mathrm{C}$ for $4 \mathrm{~min}$ with $10 \mathrm{~s}$ intervals. Specific acitvity of catalase was calculated from the equation: specific activity (units $/ \mathrm{mg}$ of protein $/ \mathrm{min})=\Delta \mathrm{A}_{240 \mathrm{~nm}}(1 \mathrm{~min}) \times 1000 /$ 43.6xmg protein.Glutathione peroxidase (GPx) activity was determined by using a commercially available kit (Sigma).

The following solutions were added to a cuvette: $900 \mu \mathrm{l}$ of GPx assay buffer containing $50 \mathrm{mM}$ Tris/ $\mathrm{HCl}, \mathrm{pH} 7.0$ and $0.5 \mathrm{mM}$ EDTA; $50 \mu \mathrm{l}$ of NADPH assay reagent containing $1.6 \mathrm{mM} \mathrm{GSH}, 0.32 \mathrm{mM} \mathrm{NADPH}$ and 10 units $/ \mathrm{ml}$ of glutathione reductase; $40 \mu \mathrm{l}$ of sample $(0.2-0.3 \mathrm{mg}$ of total cellular protein); $10 \mu \mathrm{l}$ of $30 \mathrm{mM} t \mathrm{BOOH}$. The absorbance at $340 \mathrm{~nm}$ was measured for 4 min with $5 \mathrm{~s}$ intervals. Results were expressed as units of specific activity defined by the amount of enzyme that consumes $1 \mathrm{mmol}$ of $\mathrm{NADPH} / \mathrm{min} / \mathrm{mg}$ of protein. Superoxide dismutase (SOD) activity was determined by using a commercially available kit (OxisResearch). The following solutions were 
added to a cuvette: $900 \mu \mathrm{l}$ solution containing 2-amino-2methyl-1,3-propanediol with boric acid and diethylenetriaminepentaacetic acid (DTPA, pH 8.8); $40 \mu \mathrm{l}$ of sample (0.1 $-0.5 \mathrm{mg}$ of protein); $30 \mu \mathrm{l}$ of 1-methyl-2-vinylpyridium trifluoromethanesulfonate in $\mathrm{HCl}$. After incubation at $37^{\circ} \mathrm{C}$ for $1 \mathrm{~min}, 30 \mu \mathrm{l}$ of the solution of $5,6,6 \mathrm{a}, 11 \mathrm{~b}$-tetrahydro-3,9,10-trihydroxybenzo[c]fluorene in $\mathrm{HCl}$ containing DPTA and ethanol was added to the reaction mixture. The absorbance at $525 \mathrm{~nm}$ was measured for $5 \mathrm{~min}$.

\section{Lipid peroxidation}

Levels of lipid peroxidation were detected with thiobarbituric acid (Prasad et al., 2000). Total cellular extracts were typically precipitated by mixing with 2 volumes of cold $10 \%(\mathrm{w} / \mathrm{v})$ trichloroacetic acid.

A standard curve was prepared using malondialdehyde bisdimethylacetal as the source of malondialdehyde (MDA). After centrifugation at $12,000 \times \mathrm{g}$ for $10 \mathrm{~min}$, an aliquot of supernatant was reacted with an equal volume of $0.67 \%(\mathrm{w} / \mathrm{v})$ thiobarbituric acid in a boiling water bath for $1 \mathrm{~h}$. An absorbance was read at $532 \mathrm{~nm}$ and the concentration of MDA was calculated based on a $\varepsilon$ value of 153,000 .

\section{Glutathione (GSH) assay}

Levels of glutathione were detected by using a commercially available Kit (OxisResearch). The following solutions were added to a cuvette: $800 \mu \mathrm{l}$ of potassium phosphate buffer containing DTPA and lubrol, $100 \mu \mathrm{l}$ of sample (0.1 $-0.5 \mathrm{mg}$ of protein), $50 \mu \mathrm{l}$ of chromogenic reagent. After $50 \mu \mathrm{l}$ of $30 \% \mathrm{NaOH}$ was added to the cuvette and incubated in the dark at $25^{\circ} \mathrm{C}$ for $10 \mathrm{~min}$, the absorbance was read at $400 \mathrm{~nm}$.

\section{Statistical analysis}

All the experimental data shown were repeated at least three times, unless otherwise indicated. Data were presented as the mean and S.E.M. for the indicated number of separate experiments. Statistical analysis of data was performed with one-way analysis of variance (ANOVA), and $P$-values less than 0.05 were considered significant.

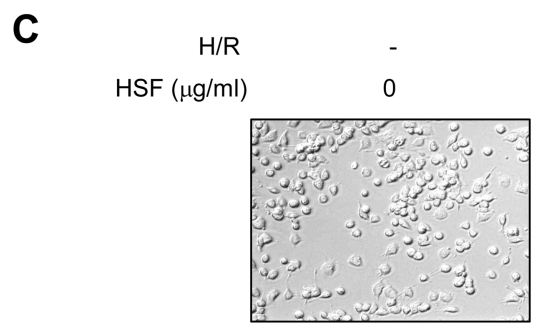

A

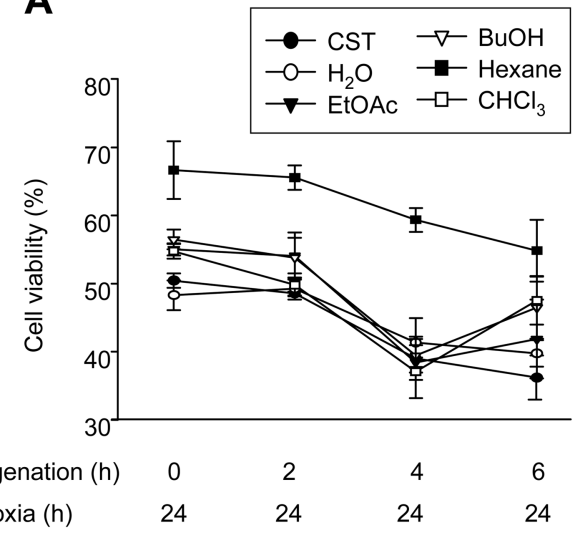

B
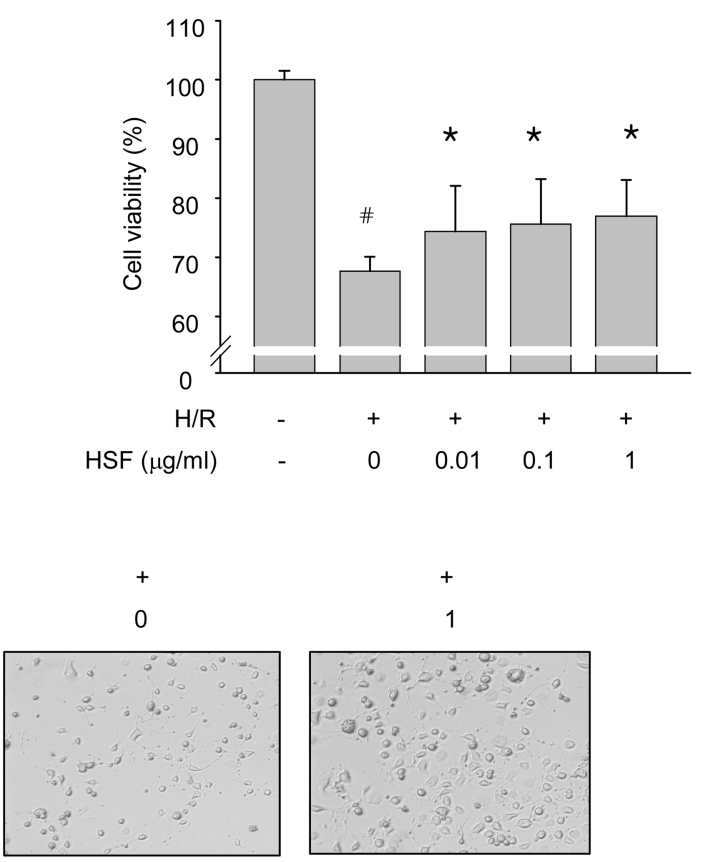

Fig. 1. Protective effect of the hexane soluble fraction (HSF) of CST on hypoxia/reoxygenation (H/R) insults in N2a cells. (A) Cells were treated with $1 \mu \mathrm{g} / \mathrm{ml}$ of solvent fractions of CST and cultured for $24 \mathrm{~h}$ in a hypoxic chamber followed by $2 \mathrm{~h}, 4 \mathrm{~h}$ and $6 \mathrm{~h}$ incubation in a $5 \% \mathrm{CO}_{2}$ incubator. (B) Cells were treated with 0 (DMSO only), $0.1,1,10 \mu \mathrm{g} / \mathrm{ml}$ of $\mathrm{HSF}$ of CST and subjected to $24 \mathrm{~h}$ hypoxia/2 $\mathrm{h}$ reoxygenation insults. (C) Phase contrast microscopic images of N2a cells cultured in $24 \mathrm{~h}$ hypoxia/2 h reoxygenation condition in the absence or presence of HSF of CST $(\times 100)$. Cells were recovered by treatment with $1 \mu \mathrm{g} / \mathrm{ml}$ of HSF from hypoxia/ reoxygenation insults. Cell viability was measured by MTT assay described in 'Materials and Methods'. bars., the mean \pm S.E.M. The asterisk $\left(^{*}\right)$ indicates a significant difference $(P<0.05)$ compared with the control $(\#)$. 


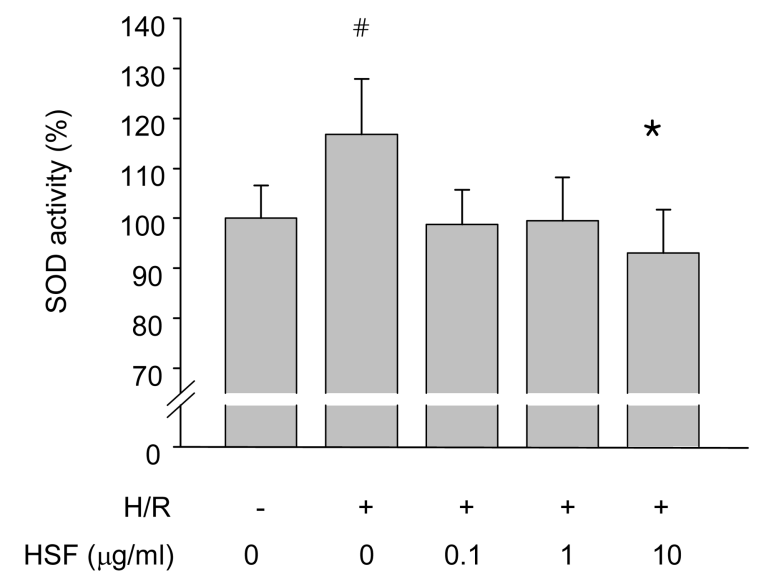

Fig. 2. Effect of the hexane soluble fraction (HSF) of CST on the activity of superoxide dismutase (SOD). Cells were treated with $0.1,1,10 \mu \mathrm{g} / \mathrm{ml}$ of HSF of CST and subjected to $24 \mathrm{~h}$ hypoxia/2 $\mathrm{h}$ reoxygenation insults. SOD activity was measured by procedures described in 'Materials and Methods'. bars., the mean \pm S.E.M. The asterisk $\left(^{*}\right)$ indicates a significant difference $(P<0.05)$ compared with the control $(\#)$.

\section{RESULTS}

\section{Protective effects of the hexane soluble fraction of CST against hypoxia/reoxygenation insults in N2a cells}

All the experimental data shown were repeated at least three times, unless otherwise indicated. To model brain strokes, in vitro, N2a cells were exposed to hypoxia/reoxygenation insults. To determine the protective effects of CST and their fractions against hypoxia/reperfusion insults, cells were exposed to hypoxia for $24 \mathrm{~h}$ followed by reoxygenation insults in the presence of $1 \mu \mathrm{g} / \mathrm{ml}$ of CST and their fractions for $2 \mathrm{~h}, 4 \mathrm{~h}$, or $6 \mathrm{~h}$, respectively. Cell viability was shown to decrease at longer time of reoxygenation after hypoxia. From these experiments it was determined that the hexane soluble fraction of CST was more protective than all other fractions of CST against hypoxia/reoxygenation insults as measured by cell viability (Fig. 1A). Cell viability of N2a cells treated with various concentrations of the hexane soluble fraction was examined under $24 \mathrm{~h}$ hypoxia/2 $\mathrm{h}$ reperfusion conditions (Fig. 1B).

In untreated samples cell viability was significantly reduced by hypoxia/reoxygenation insults $(67.7 \%$ of control) as assessed by MTT assay. However, treatment with the hexane soluble fraction increased the cell viability in a reverse concentration-dependent manner. It protected cells more effectively from hypoxia/reoxygenation insults than the other fractions. As shown in Fig. 1C, cell viabil-
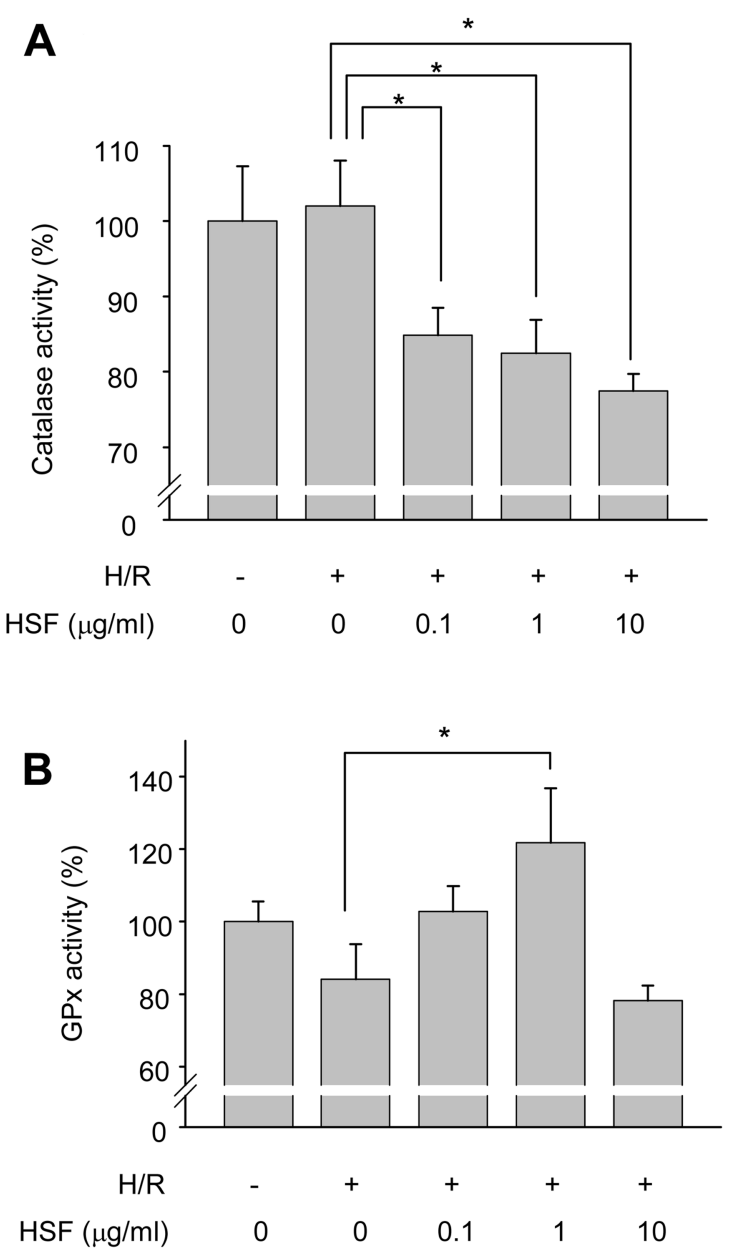

Fig. 3. Effect of the hexane soluble fraction (HSF) of CST on the activity of catalase (A) and glutathione peroxidase (GPx) (B). Cells were treated with $0.1,1,10 \mu \mathrm{g} / \mathrm{ml}$ of HSF of CST and subjected to $24 \mathrm{~h}$ hypoxia/2 $\mathrm{h}$ reoxygenation insults. Catalase and GPx activity was measured as described in 'Materials and Methods'. bars., the mean \pm S.E.M. The asterisk $\left(^{*}\right)$ indicates a significant difference $(P<0.05)$ compared with the control.

ity was decreased by hypoxia/reoxygenation insults, but cells treated with $1 \mu \mathrm{g} / \mathrm{ml}$ of hexane soluble fraction of CST were significantly protected against this effect.

Effect of the hexane soluble fraction of CST on cellular SOD, catalase and glutathione peroxidase (GPx) activity in hypoxia/reoxygenation-induced N2a cells

The activities of cellular SOD were significantly higher $(116.8 \%$ of control) in the hypoxia/reoxygenation group 

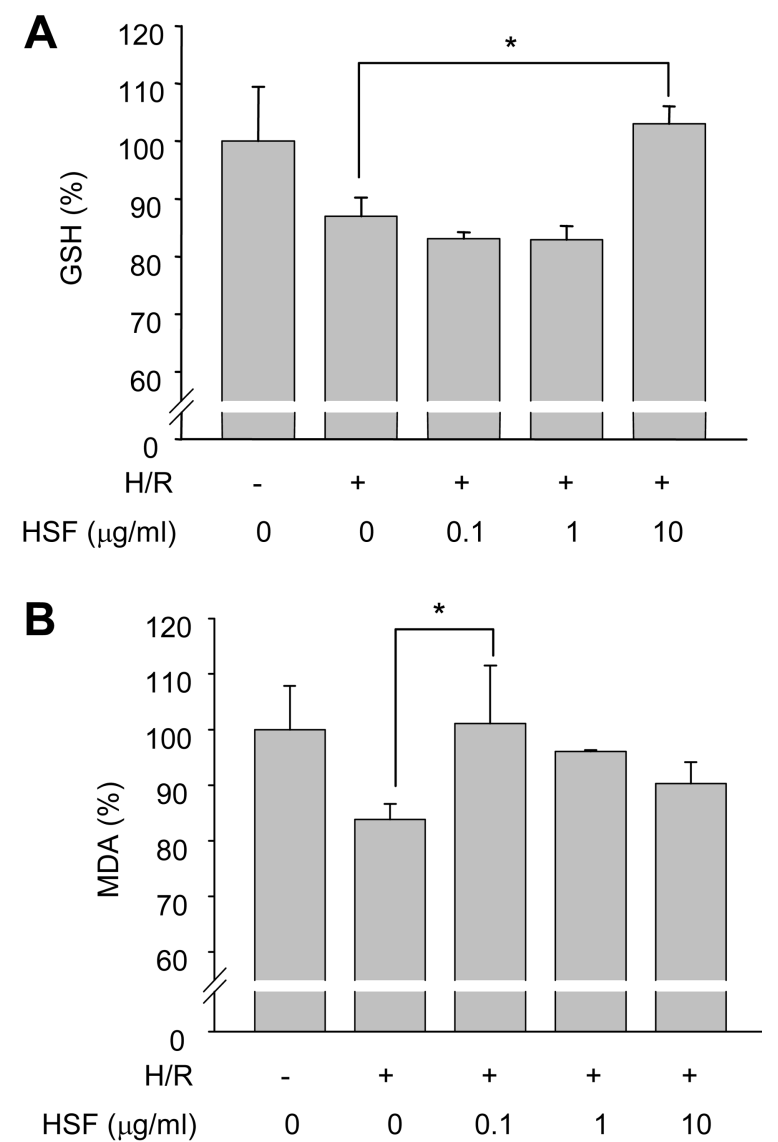

Fig. 4. Effect of hexane soluble fraction (HSF) of CST on the level of glutathione (GSH) (A) and malondialdehyde (MDA) (B). Cells were treated with $0.1,1,10 \mu \mathrm{g} / \mathrm{ml}$ of HSF of CST and subjected to $24 \mathrm{~h}$ hypoxia/2 $\mathrm{h}$ reoxygenation insults. The levels of GSH and MDA were measured as described in 'Materials and Methods'. bars., the mean \pm S.E.M. The asterisk $\left(^{*}\right)$ indicates a significant difference $(P<0.05)$ compared with the control.

relative to those in the control group (Fig. 2).

However, treatment with the hexane soluble fraction of CST was shown to restore SOD activity in a concentration-dependent manner. The activities of catalase were slightly higher in the hypoxia/reoxygenation group relative to those in the control group (Fig. 3A) but treatment with the hexane soluble fraction of CST decreased these activities in a concentration-dependent manner.

Furthermore, glutathione peroxidase (GPx) activity was slightly reduced (84.3\% of control) in the hypoxia/reoxygenation group relative to those in the control group (Fig. 3B) and treatment with $10 \mu \mathrm{g} / \mathrm{ml}$ of the hexane soluble fraction of CST increased the activity of GPx even further to $121.8 \%$. However, $10 \mu \mathrm{g} / \mathrm{ml}$ of the hexane soluble frac- tion of CST did not increase the activity of GPx.

\section{Effect of the hexane soluble fraction of CST on pro- duction of glutathione (GSH) and MDA in hypoxia/ reoxygenation-induced N2a cells}

Hypoxia/reperfusion insults decreased production of GSH in N2a cells ( $77.4 \%$ of control) relative to the control. In addition, the inhibitory effect of the hexane soluble fraction of CST on hypoxia/reoxygenation -induced GSH depletion was measured. From these experiments treatment of $10 \mu \mathrm{g} / \mathrm{ml}$ of hexane soluble fraction of CST was shown to slightly restore the GSH level reduced by hypoxia/reoxygenation insults (Fig. 4A). However, treatment of 0.1 and $1 \mu \mathrm{g} / \mathrm{ml}$ of the hexane soluble fraction of CST did not restore the level of GSH. As shown in Fig. 4B, exposing cells to hypoxia/reoxygenation insults decreased MDA formation (83.8\% of control). However, treatment with $0.1 \mu \mathrm{g} / \mathrm{ml}$ of the hexane soluble fraction of CST restored the level of MDA to $101.1 \%$.

A

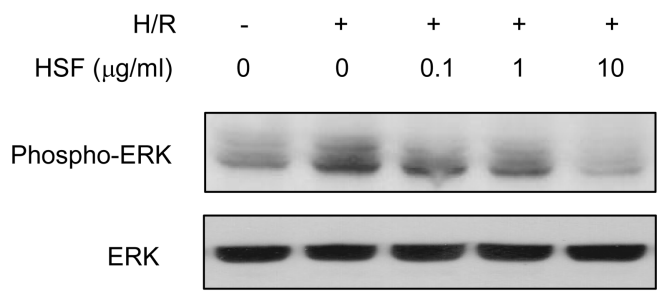

B

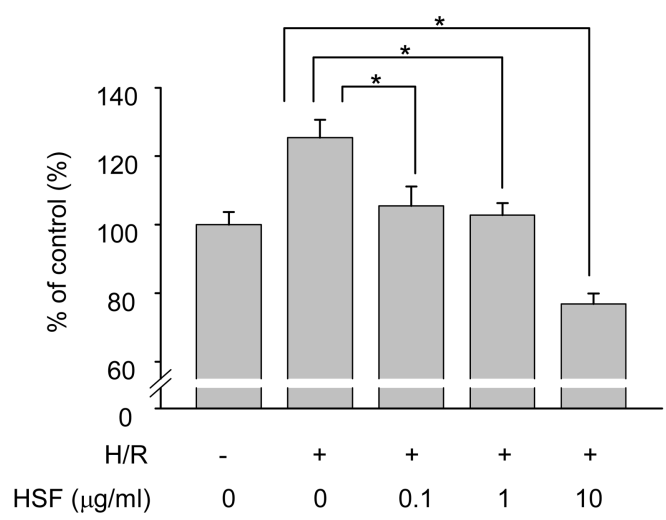

Fig. 5. Effect of hexane soluble fraction (HSF) of CST on the activity of ERK in N2a cells under hypoxia. Cells were treated with $0.1,1,10 \mu \mathrm{g} / \mathrm{ml}$ of HSF of CST and subjected to $24 \mathrm{~h}$ hypoxia/2 $h$ reoxygenation insults. The level of $p E R K$ was measured by Western blot using antibodies against pERK. The graph represents the level of pERK as the percentage of control. bars., the mean \pm S.E.M. The asterisk $\left({ }^{*}\right)$ indicates a significant difference $(P<0.05)$ compared with the control. 


\section{Effect of hexane soluble fraction of CST on the activity of ERK in hypoxia-induced N2a cells}

The activity of extracellular signal-regulated protein kinase (ERK) was increased in hypoxia/reoxygenationinduced N2a cells relative to that in the control group as shown in Fig. 5. However, treatment with the hexane soluble fraction of CST decreased these activities in a concentration-dependent manner, suggesting that the hexane soluble fraction of CST modulates redox enzymes as well as ERK to protect cells from hypoxia/reoxygenation insults.

\section{DISCUSSION}

Ischemia induces an imbalance of endogenous oxidants and antioxidants resulting in the overproduction of toxic free radicals. Reoxygenation during reperfusion provides oxygen to sustain neural viability but also provides oxygen as a substrate for numerous enzymatic oxidation reactions that produce reactive oxidants. In strokes, oxidative damage has been implicated in various modes of acute brain damage and chronic neurodegeneration, which are irreversible (Bramlett and Dietrich, 2004). Reperfusion after ischemia causes overproduction of ROS in mitochondria, and consumption of endogenous antioxidants by these radicals may lead to a dramatic rise in intracellular ROS (Chan, 2001). It has been demonstrated in numerous studies that ROS are directly involved with cellular macromolecules such as lipids, proteins, and nucleic acids in oxidative damage in ischemic tissues, which leads to cell death (Loh et al., 2006). ROS attacks can cause lipid peroxidation in the polyunsaturated fatty acids of membrane lipids, which may lead to disorganization of cell structure and function. Furthermore, decomposition of peroxidized lipids yields a wide variety of end products, including MDA (llhan et al., 1999). In particular, the brain is highly vulnerable to radical-mediated injury because neuronal membranes are rich in polyunsaturated fatty acids (Inoue et al., 1990). Recent studies have provided evidence that suggest indirect signaling pathways mediated by ROS can also cause cellular damage and death in cerebral ischemia and reperfusion (Sugawara et al., 2004).

It has been proposed that oxygen free radicals or oxidants are involved in the development of many neurological disorders and brain dysfunctions. Reperfusion results in the massive production of reactive oxygen (ROS) and nitrogen species (RNS), which can initiate brain damage through ischemia (Traystman et al., 1991). In particular, superoxide anion $\left(\mathrm{O}_{2}^{-}\right)$, one of the key mediators of excitotoxicity and disturbed $\mathrm{Ca}^{2+}$ homeostasis, plays an important role in oxidative chain reactions (Kawase et al., 1999). Therefore, accumulations of toxic free radicals not only increases the susceptibility of brain tissues to oxidative damage but also triggers various cascades of ischemic injury, which can lead to either direct injury via membranous lipid peroxidation and protein and DNA oxidation or indirect damage via inflammation and apoptosis (Chan, 2001; Kuroda and Siesjo, 1997; Traystman et al., 1991).

Several enzymes, including SOD, GPx, glutathione reductase, and catalase, are endogenous antioxidants that process specific free radical (Floyd, 1999; Lum and Roebuck, 2001; Ushio-Fukai and Alexander, 2004). SOD specifically processes superoxide anion $\left(\mathrm{O}_{2}^{-}\right)$and produces $\mathrm{H}_{2} \mathrm{O}_{2}$, which is then detoxified by catalase or GPx, and finally changed to water and molecularoxygen. In addition, Hydroxyl radicals $(-\mathrm{OH})$ may be generated from $\mathrm{H}_{2} \mathrm{O}_{2}$ through the Fenton reaction $\left(\mathrm{H}_{2} \mathrm{O}_{2}+\mathrm{Fe}^{2+} \rightarrow{ }^{-} \mathrm{OH}+\right.$ $\left.\mathrm{OH}^{-}+\mathrm{Fe}^{3+}\right)$. Other small molecular antioxidants, including GSH, ascorbic acid and $\alpha$-tocopherol, are also involved in the detoxification of free radicals (Sies and Stahl, 1995). Although several antioxidant enzymes including SOD, GPx, and catalase process those oxygen radicals, overproduced oxygen radicals exceeding the capacity of the endogenous antioxidant enzymes cause oxidative stress or injury of brain cells in pathological conditions such as ischemia (Murakami et al., 1997). Therefore, one strategy to protect the brain against ischemic-reperfusion injury is to improve the endogenous antioxidant defense in the tissues "at risk," and/or to decrease oxidative damage by scavenging toxic free radicals that are excessively produced in ischemic tissues (Kuroda and Siesjo, 1997).

In recent years, a great deal of pharmacological research has been undertaken to review and establish reliable composite formulas based on natural products used for oriental medicine to discover new drug resources (Wang et al., 1995). In particular, there are many traditional medicines used for stroke therapy in oriental medicine (Gong and Sucher, 1999). CST is one of the most frequently used herbal prescriptions for the treatment of ischemic stroke in oriental medicine. It is well known CST inhibits the advancement of strokes and restores physiological function (Hong et al., 1999). In recent reports, CST has been shown to act as antiinflammatory by inhibiting the formation of inflammationrelated molecules such as prostaglandin $\mathrm{E}_{2}$ and arachidonic acid in human neuroblastoma and monocytic macrophage cells (Hong et al., 2000). In addition, CST has been shown to promote neuroprotective effects via elimination of free radical, inhibition of lipid peroxidation and 
inhibition of xanthine oxidase in, in vitro, ischemia/reperfusion injury (Hong et al., 1999). In the present study, the hexane soluble fraction of CST was more protective than all other fractions of CST against hypoxia alone (Fig. 1A), suggesting that bioactive compounds in hexane soluble fraction effectively protect cells from hypoxic stress as well as reoxygenation insults.

The effects of hypoxia on the mitogen-activated protein kinase (MAPKs) activities are well characterized. In particular, the activation of MAPKs is a function of the degree of hypoxia. For instance, ERK and p38 kinase were activated in $5 \%$ of oxygen (Beitner-Johnson et al., 2002) whereas c-Jun $\mathrm{N}$-terminal kinase (JNK) remained unchanged. However, all three were activated under anoxia (Tabakman et al., 2004). Our data indicate that hypoxic stress leads to activation of ERK, which coincides with previous reports. In the present study the hexane soluble fraction of CST inhibited the hypoxia-induced activation of ERK.

In this study we have shown that the hexane soluble fraction of CST exhibited the highest cell viability from 24 $\mathrm{h}$ hypoxia/2 $\mathrm{h}$ reoxygenation and this protective effect appears to result from recovering redox enzyme activities and the levels of MDA and GSH. Further studies are necessary to identify the exact compounds in the hexane soluble fraction that are responsible for these protective effects against hypoxia/reoxygenation insults. In conclusion, we have determined that the hexane soluble fraction of CST exhibited the highest level of protection against N2a cell damage caused by hypoxia/reoxygenation, and this effect is most likely due to recovery of redox enzyme activities and maintenance of bioactive compound levels.

\section{REFERENCES}

Aebi, H. (1984). Catalase in vitro. Methods Enzymol. 105, 121126.

Beitner-Johnson, D., Ferguson, T., Rust, R. T., Kobayashi, S., and Millhorn, D. E. (2002). Calcium-dependent activation of Pyk2 by hypoxia. Cell Signal. 14, 133-137.

Bramlett, H. M. and Dietrich, W. D. (2004). Pathophysiology of cerebral ischemia and brain trauma: similarities and differences. J. Cereb. Blood Flow Metab. 24, 133-150.

Chan, P. H. (2001). Reactive oxygen radicals in signaling and damage in the ischemic brain. J. Cereb. Blood Flow Metab. 21, 2-14.

Flaskos, J., McLean, W. G., Fowler, M. J. and Hargreaves, A. J. (1998). Tricresyl phosphate inhibits the formation of axon-like processes and disrupts neurofilaments in cultured mouse N2a and rat PC12 cells. Neurosci. Lett. 242, 101-104.

Floyd, R. A. (1999). Neuroinflammatory processes are impor- tant in neurodegenerative diseases: an hypothesis to explain the increased formation of reactive oxygen and nitrogen species as major factors involved in neurodegenerative disease development. Free Radic. Biol. Med. 26, 1346-1355.

Gong, X. and Sucher, N. J. (1999). Stroke therapy in traditional Chinese medicine (TCM): prospects for drug discovery and development. Trends Pharmacol. Sci. 20, 191-196.

Hong, S. G., Kang, B. J. and Cho, D. W. (2000). Inhibitory effects of Chungpesagan-tang on ischemia/reperfusioninduced inflammatory responses in vitro. KIOM Journal 6, 8187.

Hong, S. G., Kang, B. J., Kim, Y. J., Kang, S. M. and Cho, D. W. (1999). Protective effects of Chungpesagan-tang against ischemia/reperfusion induced cell injury. KIOM Journal 5, 111117.

Huang, Y. and McNamara, J. O. (2004). Ischemic stroke: "acidotoxicity" is a perpetrator. Cell 118, 665-666.

Huet, O., Petit, J. M., Ratinaud, M. H. and Julien, R. (1992). $\mathrm{NADH}$-dependent dehydrogenase activity estimation by flow cytometric analysis of 3-(4,5-dimethylthiazolyl-2-yl)-2,5-diphenyltetrazolium bromide (MTT) reduction. Cytometry 13, 532539.

Ilhan, A., Koltuksuz, U., Ozen, S., Uz, E., Ciralik, H. and Akyol, O. (1999). The effects of caffeic acid phenethyl ester (CAPE) on spinal cord ischemia/reperfusion injury in rabbits. Eur. J. Cardiothorac. Surg. 16, 458-463.

Inoue, M., Watanabe, N., Morino, Y., Tanaka, Y., Amachi, T. and Sasaki, J. (1990). Inhibition of oxygen toxicity by targeting superoxide dismutase to endothelial cell surface. FEBS Lett. 269, 89-92.

Kawase, M., Murakami, K., Fujimura, M., Morita-Fujimura, Y., Gasche, Y., Kondo, T., Scott, R. W. and Chan, P. H. (1999). Exacerbation of delayed cell injury after transient global ischemia in mutant mice with CuZn superoxide dismutase deficiency. Stroke 30, 1962-1968.

Kuroda, S. and Siesjo, B. K. (1997). Reperfusion damage following focal ischemia: pathophysiology and therapeutic windows. Clin. Neurosci. 4, 199-212.

Lee, H. C., Kim, D. W., Jung, K. Y., Park, I. C., Park, M. J., Kim, M. S., Woo, S. H., Rhee, C. H., Yoo, H., Lee, S. H. and Hong, S. I. (2004). Increased expression of antioxidant enzymes in radioresistant variant from U251 human glioblastoma cell line. Int. J. Mol. Med. 13, 883-887.

Li, C. and Jackson, R. M. (2002). Reactive species mechanisms of cellular hypoxia-reoxygenation injury. Am. J. Physiol. Cell. Physiol. 282, C227-241.

Loh, K. P., Huang, S. H., De Silva, R., Tan, B.K. and Zhu, Y. Z. (2006). Oxidative stress: apoptosis in neuronal injury. Curr. Alzheimer Res. 3, 327-337.

Lum, H. and Roebuck, K. A. (2001). Oxidant stress and endothelial cell dysfunction. Am. J. Physiol. Cell. Physiol. 280, C719-741.

Murakami, K., Kondo, T., Epstein, C.J. and Chan, P. H. (1997). Overexpression of $\mathrm{CuZn}$-superoxide dismutase reduces hippocampal injury after global ischemia in transgenic mice. Stroke 28, 1797-1804.

Prasad, K., Mantha, S. V., Muir, A. D. and Westcott, N. D. (2000). Protective effect of secoisolariciresinol diglucoside 
against streptozotocin-induced diabetes and its mechanism. Mol. Cell. Biochem. 206, 141-149.

Sies, H. and Stahl, W. (1995). Vitamins E and C, beta-carotene, and other carotenoids as antioxidants. Am. J. Clin. Nutr. 62, 1315S-1321S.

Sugawara, T., Fujimura, M., Noshita, N., Kim, G. W., Saito, A., Hayashi, T., Narasimhan, P., Maier, C.M. and Chan, P. H. (2004). Neuronal death/survival signaling pathways in cerebral ischemia. NeuroRx. 1, 17-25.

Tabakman, R., Jiang, H., Levine, R. A., Kohen, R., and Lazarovici, P. (2004). Apoptotic characteristics of cell death and the neuroprotective effect of homocarnosine on pheochromocytoma PC12 cells exposed to ischemia. J. Neurosci. Res. 75, 499-507.
Traystman, R. J., Kirsch, J. R. and Koehler, R. C. (1991). Oxygen radical mechanisms of brain injury following ischemia and reperfusion. J. Appl. Physiol. 71, 1185-1195.

Ushio-Fukai, M. and Alexander, R. W. (2004). Reactive oxygen species as mediators of angiogenesis signaling: role of NAD(P)H oxidase. Mol. Cell Biochem. 264, 85-97.

Venardos, K. M., Perkins, A., Headrick, J. and Kaye, D. M. (2007). Myocardial ischemia-reperfusion injury, antioxidant enzyme systems, and selenium: a review. Curr. Med. Chem. 14, 1539-1549.

Wang, Z. T., Ng, T. B. and Xu, G. J. (1995). Recent advances in pharmacognosy research in China. Gen. Pharmacol. 26, 1211-1224. 